\title{
GMR
}

\section{Genetic relatedness of artichoke (Cynara scolymus L.) hybrids using random amplified polymorphic DNA (RAPD) fingerprinting}

\author{
M.A. Sharaf-Eldin ${ }^{1,2}$, A. Al-Tamimi ${ }^{3}$, P. Alam ${ }^{1}$, S.F. Elkholy ${ }^{1,4}$ and J.R. Jordan ${ }^{5}$ \\ 1Sara Alghonaim Research Chair, Biology Department, \\ College of Science and Humanities, Prince Sattam bin Abdulaziz University, Alkharj, \\ Kingdom of Saudi Arabia \\ ${ }^{2}$ Department of Medicinal and Aromatic Plants Research, \\ National Research Centre, Cairo, Egypt \\ ${ }^{3}$ Biology Department, Princess Noura University, Riyadh, Saudi Arabia \\ ${ }^{4}$ Plant Transformation and Biopharmaceuticals Lab, \\ Agricultural Genetic Engineering Research Institute, \\ Agricultural Research Centre, Giza, Egypt \\ ${ }^{5}$ Big Heart Seed, Brawley, CA, USA \\ Corresponding author: M.A. Sharaf-Eldin \\ E-mail: sharafeldin99@yahoo.com \\ Genet. Mol. Res. 14 (4): 18431-18439 (2015) \\ Received August 28, 2015 \\ Accepted November 13, 2015 \\ Published December 23, 2015 \\ DOI http://dx.doi.org/10.4238/2015.December.23.31
}

ABSTRACT. The artichoke (Cynara scolymus L.) is an important food and medicinal crop that is cultivated in Mediterranean countries. Morphological characteristics, such as head shape and diameter, leaf shape, and bract shape, are mainly affected by environmental conditions. A molecular marker approach was used to analyze the degree of polymorphism between artichoke hybrid lines. The degree of genetic difference among three artichoke hybrids was evaluated using random amplified polymorphic DNAPCR (RAPD-PCR). In this study, the DNA fingerprints of three artichoke lines (A13-010, A11-018, and A12-179) were generated, and a total of 10 decamer primers were applied for RAPD-PCR analyses. Polymorphism 
(16.66 to $62.50 \%$ ) was identified using eight arbitrary decamers and total genomic DNA extracted from the hybrids. Of the 59 loci detected, there were 25 polymorphic and 34 monomorphic loci. Jaccard's similarity index (JSI) ranged between 1.0 and 0.84 . Based on the unweighted pair group method with arithmetic mean (UPGMA) similarity matrix and dendrogram, the results indicated that two hybrids (A13-010 and A11-018) were closely related to each other, and the A12-179 line showed more divergence. When identifying correct accessions, consideration of the genetic variation and genetic relationships among the genotypes are required. The RAPDPCR fingerprinting of artichoke lines clearly showed that it is possible to analyze the RAPD patterns for correlation between genetic means and differences or resemblance between close accessions (A13-010 and A11018) at the genomic level.

Key words: Genetic relationship; PCR; RAPD; Polymorphism

\section{INTRODUCTION}

The artichoke (Cynara scolymus L., Asteraceae) is a diploid $(2 n=2 x=34)$ perennial outcrossing species or ecotype that grows in Mediterranean countries (Grieve, 1971; Leung and Foster, 1996). Moreover, it is an ancient herbaceous perennial plant that originated in the southern Mediterranean parts of North Africa. Today, artichokes are widely grown or introduced around the world, and Italy and Spain are the world's leading producers (Iwu, 1993). The plant grows to 1.5 to $2 \mathrm{~m}$ tall, and it has arching, deeply lobed, silvery glaucous-green leaves that are 50 to $80 \mathrm{~cm}$ long. The artichoke leaves have been widely used in traditional herbal medicine as a choleretic since ancient times (Nasser, 2012). The artichoke head, an immature flower, constitutes the edible part of this vegetable. Furthermore, artichokes or globe artichokes can be used as edible materials for nutrition in addition to medically active cynarin and chlorogenic acid, which are phenolic acid constituents (Evans, 2009). A high number of artichoke ecotypes exist worldwide, and more than 70 artichoke varieties have been characterized based on the physiochemical properties (Dellacecca et al., 1976; Hammouda et al., 1993; Elia and Miccolis, 1996). However, the same variety or cultivar can sometimes receive a different name based on the cultivation country, and this leads to great confusion when determining the correct accession. Therefore, a specific molecular marker system is urgently required to identify the correct accessions.

For many crop species, genetic relationships based on molecular markers are consistent with expectations founded on pedigrees and breeding behaviors. However, estimates using genetic variability techniques (e.g., analysis of physiochemical markers) do not reveal sufficient levels of polymorphism that can be used to detect genetic differences among genotypes (Goodman and Stuber, 1980; Smith, 1984). The analysis of random amplified polymorphic DNA (RAPD) is a useful molecular marker technique, which uses PCR to differentiate between plant genomes at the DNA level (Williams et al., 1990). The variability and polymorphism deduced from the genomic DNA banding pattern in the electrophoretic profile result from differences in the primer binding sites.

PCR-based RAPD (Williams et al., 1990) molecular markers are relatively inexpensive and easy to generate. Compared to other DNA-based markers, the RAPD technique is a simple and inexpensive molecular marker technique, so it has been used to differentiate between close variants of several plant species, including Typhonium species (Acharya et al., 2005), Dendrobium 
species (Zhang et al., 2005), Tinospora cordifolia (Rout, 2006), artichoke (Tivang et al., 1996), Echinacea (Nieri et al., 2003), Curcuma longa (Sasikumar et al., 2004), Astragali radix (Na et al., 2004), Cynara cardunculus (Cravero , 2007), and Dendrobium officinale (Ding et al., 2005).

The phylogenetic relationships of artichokes (Goodspeed, 1954) and the large-scale variation in genome size associated with species differentiation provide the basis for molecular comparisons of plants. Molecular phylogenetic analyses have not been extensively used as a systematic tool to study species differentiation and evolution at the genus level. The goals of this study were to measure genetic relationships among three artichoke hybrid cultivars (A13-010, A11-018, and A12-179) using RAPD-PCR based markers and to determine the degree of genetic similarity and variability between cultivars.

\section{MATERIAL AND METHODS}

\section{Plant material}

The leaves of three hybrid artichoke lines were collected from the experimental farm station of Sara Alghonaim Research Chair, Alkharj, Saudi Arabia (Figure 1). The plants were maintained under recommended agricultural conditions, which were suggested by Big Heart Seed Company (California, USA).

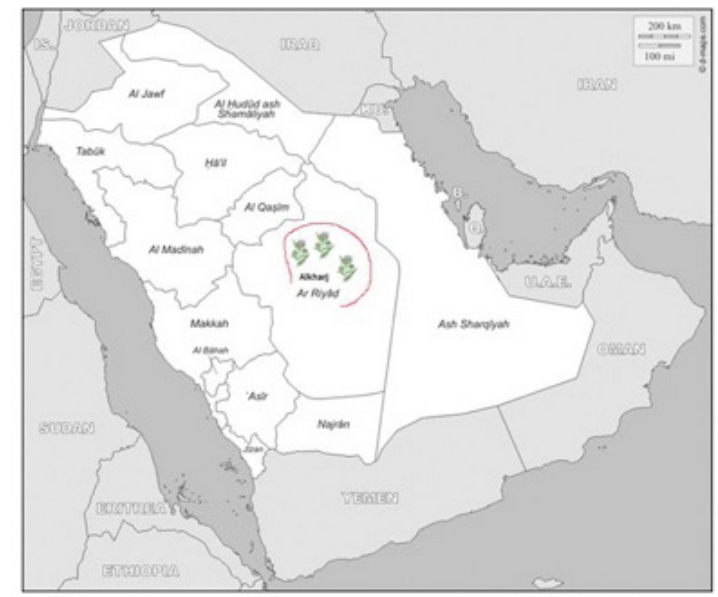

Figure 1. Geographical map of Alkharj, Saudi Arabia.

\section{DNA Extraction and purification}

Genomic DNA was extracted from the leaf samples of three artichoke genotypes (A13010, A11-018, and A12-179) according to the manufacturer instructions (Wizard ${ }^{\circledR}$ Genomic DNA Purification Kit, Promega, USA). Briefly, $40 \mathrm{mg}$ of each plant leaf was thoroughly homogenized in liquid nitrogen. A total of $600 \mu \mathrm{L}$ nuclei lysis solution was added, and the tubes were incubated at $65^{\circ} \mathrm{C}$ for $15 \mathrm{~min}$. To remove RNA contamination, $3 \mu \mathrm{L}$ RNase solution was added to each tube, and tubes were incubated for $15 \mathrm{~min}$ at $37^{\circ} \mathrm{C}$. Tubes were cooled to room temperature, and $300 \mu \mathrm{L}$ protein precipitation solution was added. The resulting mixture was vortexed, and was 
then centrifuged at $13,000 \mathrm{rpm}$ for $3 \mathrm{~min}$. The supernatant was transferred to a microfuge tube containing $300 \mu \mathrm{L}$ isopropanol, mixed slightly by inversion, and centrifuged at 13,000 rpm for $1 \mathrm{~min}$. DNA pellets were washed twice using $70 \%$ ethanol, and were then rehydrated using DNA hydration solution (Wizard ${ }^{\circledR}$ Genomic DNA Purification Kit) for $1 \mathrm{~h}$ at $65^{\circ} \mathrm{C}$. The isolated DNA from the A13010, A11-018, and A12-179 genotypes were then quantified by measuring the OD of the DNA solution at 260 and $280 \mathrm{~nm}$ using a UV-VIS spectrophotometer (BMG LABTECH, Germany). The purity of the DNA samples was checked by calculating the absorbance ratio of the DNA solution at 260 and $280 \mathrm{~nm}$. The quality of extracted DNA was examined via agarose gel electrophoresis on a $1 \%$ agarose gel in $1 \mathrm{X}$ TBE at $100 \mathrm{~V}$. The gel was visualized under a UV trans-illuminator, and was photographed using a BioRad Gel Documentation system (Bio-Rad, Germany).

\section{Generation of RAPD markers}

The DNA samples were extracted from A13-010, A11-018, and A12-179 leaf samples, and plants were subjected to RAPD analyses. PCR amplification was performed using 10 sets of arbitrary decamer primers (Table 1), which were chosen randomly and procured from e-oligos (Hawthorne, USA). Amplification reactions were performed in $25 \mu \mathrm{L}$ reaction volumes containing the following components: $2 \mu \mathrm{L}$ DNA template (15 ng/ $\mu \mathrm{L}), 2 \mu \mathrm{L}$ dNTPs mix $(2.5 \mathrm{mM}), 0.5 \mu \mathrm{L}$ Taq DNA polymerase, $2.5 \mu \mathrm{L} 10 \mathrm{X}$ reaction buffer, and $5 \mathrm{pM}$ random primer. The final volume was adjusted to $25 \mu \mathrm{L}$ with distilled water. PCR amplification was conducted using a Gene Amp PCR system 9700 thermal cycler (Applied Biosystems, USA), and the following conditions were used: initial denaturation at $94^{\circ} \mathrm{C}$ for $5 \mathrm{~min} ; 40$ cycles of denaturation at $94^{\circ} \mathrm{C}$ for $1 \mathrm{~min}$; annealing at $50^{\circ} \mathrm{C}$ for $1 \mathrm{~min}$; and extension at $72^{\circ} \mathrm{C}$ for $2 \mathrm{~min}$. The samples were then subjected to long extension at $72^{\circ} \mathrm{C}$ for $10 \mathrm{~min}$ with a hold temperature of $4^{\circ} \mathrm{C}$. PCR products were visualized on a $1.2 \%$ agarose gel, which was subsequently photographed.

Table 1. Ten arbitrary primers used for RAPD-PCR analysis of three artichoke hybrids.

\begin{tabular}{ll}
\hline Primer & Sequence $5^{\prime}-3^{\prime}$ \\
\hline EO1 & CCTTGACGCA \\
EO2 & TGCTCTGCC \\
EO3 & GTTTCGCTCC \\
EO4 & TGATCCCTGG \\
EO5 & CATCCCCCTG \\
EO6 & GGACTGGAGT \\
EO7 & TGCGCCTCC \\
EO8 & GGTGACGCAG \\
EO9 & CTCCACACGG \\
EO10 & TGGGGGCTC \\
\hline
\end{tabular}

\section{Phylogenetic grouping using RAPD fingerprints}

To identify RAPD markers, 10 primer sets were designed to amplify all possible polymorphic reproducible bands, and these primers were used for initial screening against three randomly chosen artichoke hybrids. Each sample was run in triplicate during PCR to verify reproducibility. The RAPD markers were named based on the primer code provided by the manufacturer (e-oligos, Hawthorne, USA), which corresponded to the 10-mer oligo primers used, followed by a four-digit number that indicated the product size (bp; Table 1). The phenotype of each RAPD marker was scored as 1 or 0 , indicating amplification or no amplification, respectively. A genotype cluster 
analysis was performed, and a dendrogram was drawn based on Jaccard's similarity coefficients (Jaccard, 1908) and unweighted pair group method with arithmetic mean (UPGMA) analyses. The NTSYS-PC version 2.0 program (Rohlf, 2001) was used to construct the dendrogram.

\section{RESULTS AND DISCUSSION}

The RAPD technique was used to assess the genetic divergence between three hybrid artichoke species, (collected in Saudi Arabia), and the reliability of the technique was also tested. The leaf morphology of the three species was similar, but the head/inflorescence morphology was different (Figure 2). Using genomic DNA as a template, we conducted the RAPD technique in triplicate using 10 sets of arbitrary decamer primers for reproducibility. The advantages of the RAPD technique include its simplicity, rapidity, the low amount of genomic DNA required, and the fact that radioisotopes and prior genetic information are not required (Williams et al., 1990). The reproducibility of RAPD is affected by DNA quality, the primer and template concentrations, and the use of different thermal cyclers and sources of DNA polymerase (Ellsworth et al., 1993; Muralidharan and Wakeland, 1993). Under the PCR conditions described above, the highest number of bands was obtained (Figures 3 and 4). This result could be due to the low annealing temperature maintained for RAPD in the present study, which might have allowed the maximum primer-DNA annealing and the maximum number of amplicons. These parameter types were also used by other investigators in studies of different plant species (Miller and Bayer, 2001; Busconi et al., 2006; Khan et al., 2010; Srivastava et al., 2012).

Across the three studied hybrids, the selected primers (EO-1 to EO-9) amplified DNA fragments that varied from 6 to 10 bands, and the size of the amplicons varied from 200 to 1500 bp. Of the 59 detected loci, 25 polymorphic and 34 monomorphic loci were identified. All of the artichoke hybrid species were differentiated based on the presence or absence of polymorphic and monomorphic fragments in the RAPD profile. Table 2 represents the total number of polymorphic and monomorphic fragments that were specific to each hybrid based on different random primers. In the present study, only eight RAPD primers out of the 10 arbitrary primer sets produced 25 polymorphic bands that unambiguously differentiated the three artichoke hybrid lines (A13-010, A11-018, and A12-179; Figures 3 and 4, Table 1). Using eight decamer primers, these RAPD molecular markers exhibited 16.66 to $62.50 \%$ polymorphism among these species (Table 2, Figures 3 and 4). Maximum polymorphism was exhibited by the EO-1 primer, followed by other primers (EO1 to EO10), but EO-2 and EO-10 exhibited no amplification (Table 2).
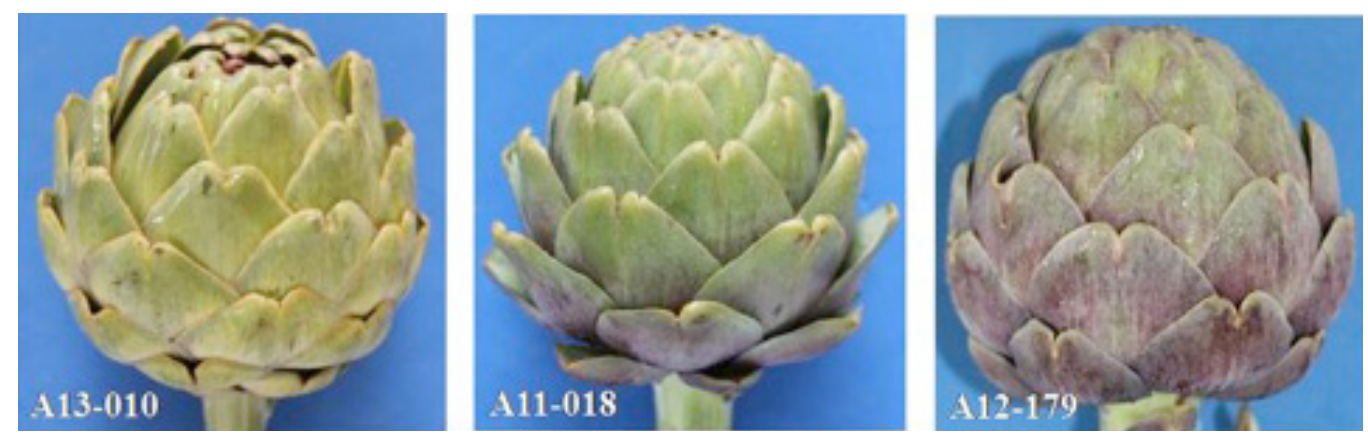

Figure 2. Morphology of the artichoke head. 


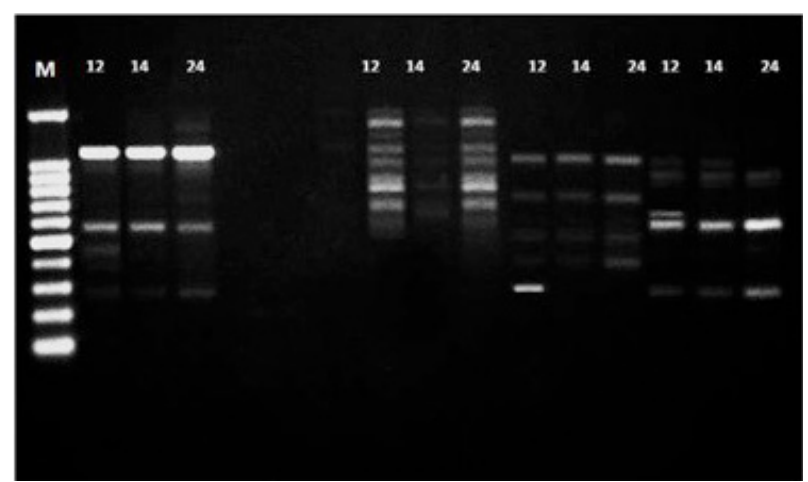

Figure 3. RAPD-PCR analyses performed using five arbitrary primer sets. Lane 2: EO-1; Lane 3: EO-2; Lane 4: EO-3; Lane 4: EO-4; Lane 5: EO-5; and M: 1.5 kb DNA ladder (EO denotes random decamers). Hybrid artichoke lines: $12=$ A13-010, $14=\mathrm{A} 11-018$, and $24=\mathrm{A} 12-179$.

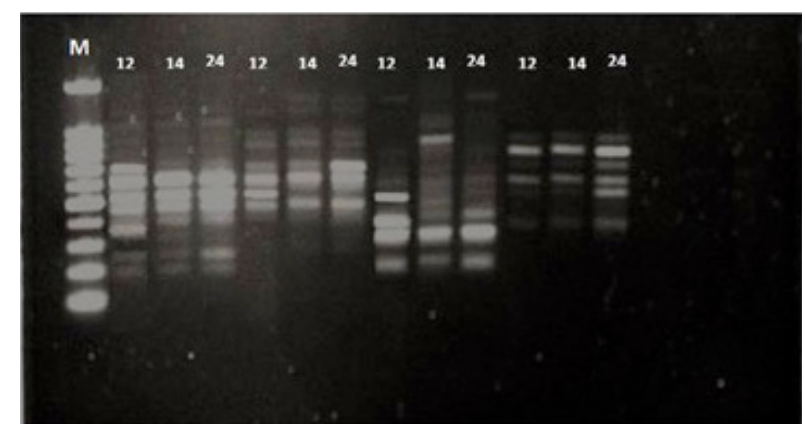

Figure 4. RAPD-PCR analyses performed using five arbitrary primer sets. Lane 2: EO-6; Lane 3: EO-7; Lane 4: EO-8; Lane 4: EO-9; Lane 5: EO-10; and M: 1.5 kb DNA ladder (EO denotes random decamers). Hybrid artichoke lines: 12 $=\mathrm{A} 13-010,14=\mathrm{A} 11-018$, and $24=\mathrm{A} 12-179$.

Table 2. Polymorphism analysis of three hybrid artichoke lines.

\begin{tabular}{|c|c|c|c|c|c|c|}
\hline \multirow[t]{2}{*}{ Primers } & \multicolumn{2}{|c|}{ Total number of bands } & \multicolumn{3}{|c|}{ Amplified polymorphic fragments in hybrid artichoke species (size, bp) } & \multirow[t]{2}{*}{$\%$ polymorphism } \\
\hline & Polymorphic & Monomorphic & A13-010 & A11-018 & A12-179 & \\
\hline EO-1 & 5 & 3 & $300-1500$ & $300-1500$ & $300-1500$ & 62.50 \\
\hline EO-2 & - & - & - & - & - & No amplification \\
\hline EO-3 & 3 & 5 & $600-1500$ & $600-1500$ & $600-1500$ & 37.50 \\
\hline EO-4 & 2 & 4 & $300-1000$ & $300-1000$ & $300-1000$ & 33.33 \\
\hline EO-5 & 3 & 3 & $300-900$ & $300-900$ & $300-900$ & 50.00 \\
\hline EO-6 & 5 & 5 & $200-1500$ & $200-1500$ & $200-1500$ & 50.00 \\
\hline EO-7 & 1 & 4 & $400-1500$ & $400-1500$ & $400-1500$ & 20.00 \\
\hline EO-8 & 5 & 5 & $200-1500$ & $200-1500$ & $200-1500$ & 50.00 \\
\hline EO-9 & 1 & 5 & $300-900$ & $300-900$ & $300-900$ & 16.66 \\
\hline EO-10 & - & - & - & - & - & No amplification \\
\hline
\end{tabular}

Thus, our results indicated that wide genetic variations among the three hybrid artichoke lines were quite diverse. This result might be due to variations in the DNA sequence that led to polymorphism, and greater polymorphism is indicative of greater genetic diversity among species. All three artichoke lines were differentiated from each other based on polymorphic bands produced 
during PCR amplification.

Artichoke hybrid line A13-010 had a 0,1,1,1,1,1,1, 1, 0, 0 maximum amount of polymorphic bands with primer EO- 6 and $0,0,1,1,1,1,1,1,1,1$ with EO-8, followed by another set of arbitrary primers (Table 1). Similarly, other artichoke hybrid lines showed different patterns with these primers, and these bands were reproducible when the PCR reaction was conducted three times. Among the 10 arbitrary primer sets, only EO-6 and EO-8 produced maximum numbers of polymorphic bands, so these primers might be used in the future for the identification and detection of these hybrid lines. DNA molecular markers have potential reproducibility under variable conditions, and they have been used in many studies to authenticate the correct cultivar.

Moreover, DNAmolecular markers provide more information as compared to physiochemical markers. Determination of intraspecific genetic diversity is an important first step for the utilization of genetic resources, and it can provide useful information on crop evolution (Sonnante et al., 2002). Using the polymorphism data detected between the artichoke species that were analyzed using RAPD fingerprinting, a similarity matrix was obtained after multi-variant analysis using the "Nei and Li" coefficient (Figure 5). The results of the genetic similarity matrix coefficient analysis indicated approximately 84 to $98 \%$ similarity between artichoke lines A13-010, A11-018, and A12179. The dendrogram illustrates the close distances between the artichoke hybrid lines, which occur at the adjacent tips of the classification according to the numerical taxonomy. Genetic diversity is important to the breeder, because the genetic variation present in breeding populations ultimately determines the potential for making gains from selection.

Mean genetic distance within populations (Figure 5) indicated that the population samples surveyed in this study could be ranked because of varying degrees of variation (Tivang et al., 1996). The RAPD-PCR banding patterns were further analyzed using UPGMA to monitor Jaccard's similarity index (JSI). The UPGMA dendrogram (Figure 5) showed two main clusters between the accessions (JSI 0.84 and 0.90). The values were between 1 (A13-010 and A11-18) and 0.84 (accession A12179) when all of the samples are considered, and one cluster split at a JSI of 0.84 . The node at a $\mathrm{JSI}$ of 0.90 separated the two cultivated artichokes (grouped with A13-010 and A11-018) from the other accessions (JSI is 1). However, A12-179 often showed similarity values that were similar and sometimes higher compared to the other artichoke accessions. This result may be due to either seed dispersal or seedling transport by migrating people for medicinal and other uses. Genetic variations observed in some of the accessions were very narrow for artichoke lines A13-010 and A11-018, which might be due to less distance between accessions or changes in the genomic sequence by environmental effects. This study showed that the RAPD technique could be used as an inexpensive, efficient tool for the identification of differences, similarities, and phylogenetic relationships between the target genotypes. A similar observation was made in several other studies (Abdel-Tawab et al., 2001; Li et al., 2001; Sonnante et al., 2002; Heikal et al., 2007).

The artichoke hybrids A13-010, A11-018, and A12-179 have extensive leaf morphology similarities, and it is very difficult to differentiate between the lines in a dry state. However, using RAPD analysis, the hybrids exhibited genetic variations based on their DNA banding patterns (size and number). The RAPD-PCR method is rapid, reproducible, and cost-effective. Moreover, it does not require genetic information from closely related plant species prior to the start of the experiment. An important consideration for the classification and utilization of germplasm resources and breeding is knowledge of genetic variation and genetic relationships among the genotypes. The DNA fingerprinting of artichoke species clearly showed that it is possible to analyze the RAPD patterns for correlations between genetic means and the distance between the species. Furthermore, this information could be used to predict the species origin at a greater level. 
The main goals of this study were to gain additional knowledge regarding artichoke genetic variation and to investigate associated interrelationships. Moreover, reproducible DNA markers, such as inter-simple sequence repeat (ISSR) and sequence characterized amplified regions (SCAR), might also be developed in the future, which could enhance the ability to authenticate species and plant lines. Therefore, regarding the identification of commercial artichoke lines, RAPD-PCR may be a rewarding technique. It could also be a useful tool for the supplementation of uniformity, distinctness, and stability analyses for artichoke lines, which could maintain their original identity for future crop protection.

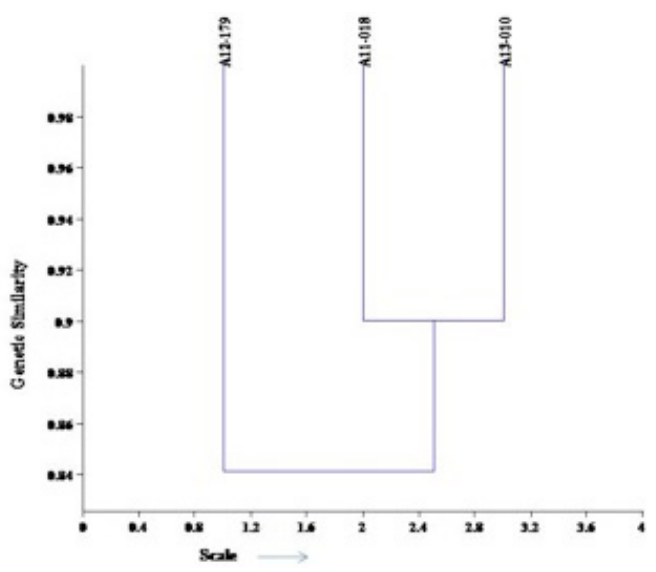

Figure 5. Genetic similarity matrix based on RAPD data among three hybrid artichoke lines.

\section{Conflicts of interest}

The authors declare no conflict of interest.

\section{ACKNOWLEDGMENTS}

Research supported by the Sara bint Rached bin Ghonaim Research Chair for Cultivating Non-Traditional Medicinal and Aromatic Plants, Biology Department, College of Science and Humanities, Prince Sattam bin Abdulaziz University, Alkharj, Kingdom of Saudi Arabia. The authors thank Mr. A. Algorashy and Mr. A. Abou-Elkhair for their help with fieldwork. The authors acknowledge critical reviews and edits of the manuscript by Ms. Hailey M. Cambra from the Department of Biology and Biotechnology at Worcester Polytechnic Institute (WPI), USA.

\section{REFERENCES}

Abdel-Tawab FM, Rashed MA, El Domyati FM, Salam TZ, et al. (2001). Marker assisted selection for salt tolerance in maize (Zea mays L.). Egypt. J. Genet. Cytol. 29: 175-181.

Acharya L, Mukherjee AK, Panda PC and Das P (2005). Molecular characterization of five medicinally important species of Typhonium (Araceae) through random amplified polymorphic DNA (RAPD). Z. Naturforsch. C 60: 600-604.

Busconi M, Sebastiani L and Fogher C (2006). Development of SCAR markers for germplasm characterisation in olive tree (Olea europaea L). Mol. Breed. 17: 59-68.

Cravero V (2007). Genetic diversity in Cynara cardunculus determined by sequence-related amplified polymorphism markers. J. Amer. Soc. Hort. Sci. 132: 208-212.

Dellacecca VV, Magnifico V, Marzi V, Porceddu E, et al. (1976). Contributo allaconoscenzadellevarieta'di carciofo coltivaten 
elmondo. Proceedings of the III International Congress on Artichoke, Bari 1973. Minerva Medica, Torino.

Ding G, Ding XY, Shen J, Tang F, et al. (2005). Genetic diversity and molecular authentication of wild populations of Dendrobium officinale by RAPD. Acta Pharmaceutica Sinica 40: 1028-1032.

Elia A and Miccolis V (1996). Relationship among 104 artichoke (Cynara scolymus L.) accessions using cluster analysis. Adv. Hort. Sci. 10: 158-162.

Ellsworth DL, Rittenhouse KD and Honeycutt RL (1993). Artifactual variation in randomly amplified polymorphic DNA banding patterns. Biotechniques 14: 214-216.

Evans WC (2009). Trease and Evans' pharmacognosy. Elsevier Health Sciences.

Goodman MM and Stuber CW (1980). Genetic identification of lines and crosses using isoenzyme electrophoresis. 5th Annual Corn and Sorghum Research Conference Proceedings. 10-31.

Goodspeed TH (1954). The genus Nicotiana. Chronica Botanica, Waltham.

Grieve M ( 1971). A modern herbal. Dover Publications, Inc., New York.

Hammouda FM, Self El-Nasr MM, Ismail SI and Shahat A (1993). Quantitative determination of the active constituents in Egyptian cultivated Cynara scolymus. Pharm. Biol. 31: 299-304.

Heikal AH, Abdel-Razzak HS and Hafez EE (2007). Assessment of genetic relationships among and within Cucurbita species using RAPD and ISSR markers. J. Appl. Sci. Res. 4: 515-525.

Iwu MM (1993). Handbook of African medical plants. CRC press, Boca Raton, FL.

Jaccard P (1908). Nouvelles recherchessur la distribuition florale. Bull. Soc. Vaudoise Sci. Nat. 44: 223-270.

Khan S, Mirza KJ and Abdin MZ (2010). Development of RAPD markers for authentication of medicinal plant Cuscuta reflexa. EurAsia J. Bio. Sci. 4: 1-7.

Leung AY and Foster S (1996). Encyclopedia of common natural ingredients used in food, drugs, and cosmetics, 2nd edn. John Wiley \& Sons, Inc., New York.

Li C, Fatokun CA, Ubi B, Singh B, et al. (2001). Determining genetic similarities and relationships among cowpea breeding lines and cultivars by microsatellite markers. Crop Sci. 41: 189-197.

Miller JT and Bayer RJ (2001). Molecular phylogenetics of Acacia (Fabaceae: Mimosoideae) based on chloroplast matK coding sequence and flanking trnK intron spacer regions. Am. J. Bot. 88: 697-705.

Muralidharan K and Wakeland EK (1993). Concentration of primer and template qualitatively affects products in randomamplified polymorphic DNA PCR. Biotechniques 14: 362-364.

$\mathrm{Na} \mathrm{H}$, Um J, Kim S, Koh K, et al. (2004). Molecular discrimination of medicinal Astragali radix by RAPD analysis. Immunopharmacol. Immunotoxicol. 26: 265-272.

Nasser AMAG (2012). Phytochemical study of Cynara scolymus L. (Artichoke) (Asteraceae) cultivated in Iraq, detection and identification of phenolic acid compounds cynarin and chlorogenic acid. Iraqi J. Pharm. Sci. 21: 6-13.

Nieri P, Adinolfi B, Morelli I, Breschi MC, et al. (2003). Genetic characterization of the three medicinal Echinacea species using RAPD analysis. Planta Med. 69: 685-686.

Rohlf FJ (2001). NTSYS-pc numerical taxonomy and multivariate analysis system. Version 5.1. Exeter Publishing Ltd., Setauket.

Rout GR (2006). Identification of Tinospora cordifolia (Willd.) Miers ex Hook F \& Thomas using RAPD markers. Z. Natur Forsch. C 6: 118-122.

Sasikumar B, Syamkumar S, Remya R and Zachariah TJ (2004). PCR based detection of adulteration in the market samples of turmeric powder. Food Biotech. 18: 299-306.

Smith JSC, Goodman MM and Stuber CW (1984). Variation within teosinte. III. Numerical analysis of allozyme data (Zea spp., distribution in Mexico, Guatemala and adjacent Central America). Econ. Bot. 38: 97-113.

Sonnante G, De Paolis A, Lattanzio V and Perrino P (2002). Genetic variation in wild and cultivated artichoke revealed by RAPD markers. Genet. Resour. Crop Evol. 49: 247-252.

Srivastava N, Bajpai A, Chandra R, Rajan S, et al. (2012). Comparison of PCR based marker systems for genetic analysis in different cultivars of mango. J. Environ. Biol. 33: 159-166.

Tivang J, Skroch P, Nienhuis J and De Vos N (1996). Randomly amplified polymorphic DNA (RAPD) variation among and within artichoke (Cynara scolymus L.) cultivars and breeding populations. J. Amer. Hort. Sci. 121: 783-788.

Williams JGK, Kubelik AR, Livak KJ, Rafalski JA, et al. (1990). DNA polymorphisms amplified by arbitrary primers are useful as genetic markers. Nucleic Acids Res. 18: 6531-6535.

Zhang Y, But PP, Wang Z and Shaw P (2005). Current approaches for the authentication of medicinal Dendrobium species and its products. Plant Genet. Resour. 3: 144-148. 